\title{
Queda da cobertura vacinal relacionada a faixa etária, Município do Rio de Janeiro,
}

\section{Brasil}

\author{
Decrease in the vaccination coverage related to age group, Rio de Janeiro Municipality, Brazil \\ Caída de la cobertura de vacunación relacionada com grupo de edad, Municipio de Río de Janeiro,
} Brasil

Recebido: 13/08/2021 | Revisado: 19/08/2021 | Aceito: 23/08/2021 | Publicado: 24/08/2021

\author{
Vinicius Ferreira dos Santos \\ ORCID: https://orcid.org/0000-0002-0607-3863 \\ Universidade Federal do Estado do Rio de Janeiro, Brasil \\ E-mail: niciusferreira@hotmail.com \\ Lucas Fernandes Gonçalves \\ ORCID: https://orcid.org/0000-0003-3623-9139 \\ Universidade Federal do Estado do Rio de Janeiro, Brasil \\ E-mail: lucasfernandesgon@gmail.com \\ Mary Ann Menezes Freire \\ ORCID: https://orcid.org/0000-0002-6255-9999 \\ Universidade Federal do Estado do Rio de Janeiro, Brasil \\ E-mail: mary.freire@unirio.br \\ Simone Mendes Carvalho \\ ORCID: https://orcid.org/0000-0001-8821-9725 \\ Universidade Federal do Estado do Rio de Janeiro, Brasil \\ E-mail: simone.carvalho@unirio.br
}

\begin{abstract}
Resumo
Objetivo: analisar a cobertura vacinal no munícipio do Rio de Janeiro, relacionada às faixas etárias, no período de 2013 - 2019. Metodologia: estudo descritivo ecológico, analítico, do tipo quantitativo e transversal. Cálculo de coberturas vacinais por meio da razão entre as doses aplicadas, disponíveis no sítio eletrônicos de acesso livre do Ministério da Saúde, Departamento de Informática do Sistema Único de Saúde (DATASUS/TABNET) e população alvo, registrados no Sistema de Informações sobre Nascidos Vivos (SINASC) ou estimativas populacionais encontradas na Fundação Instituto Brasileiro de Geografia e Estatística (IBGE). Resultados: os indicadores obtidos para os imunobiológicos que integram o calendário de vacinação de recém-nascidos, crianças e adolescentes revelam um cenário preocupante de acentuação da queda de cobertura vacinal, de acordo com cada faixa etária, com poucos indicadores exitosos. Conclusão: os resultados desse estudo destacam a queda na cobertura vacinal para algumas vacinas e faixas etárias. Indica a necessidade de estudos para investigação dos motivos que têm levado a essa queda na cobertura vacinal.
\end{abstract}

Palavras-chave: Saúde pública; Epidemiologia; Cobertura vacinal.

\begin{abstract}
Objective: to analyze vaccination coverage in the city of Rio de Janeiro, related to age groups, in the period 20132019. Methodology: descriptive, ecological, analytical, quantitative and cross-sectional study. Calculation of vaccine coverage through the ratio between the doses applied, available on the free access website of the Ministry of Health, Department of Informatics of the Unified Health System (DATASUS/TABNET) and target population, registered in the Information System on Live Births (SINASC) or population estimates found at the Brazilian Institute of Geography and Statistics Foundation (IBGE). Results: the indicators obtained for immunobiologicals that make up the vaccination calendar for newborns, children and adolescents reveal a worrying scenario of accentuation of the fall in vaccination coverage, according to each age group, with few successful indicators. Conclusion: the results of this study highlight the drop in vaccination coverage for some vaccines and age groups. It indicates the need for studies to investigate the reasons that have led to this drop in vaccination coverage.
\end{abstract}

Keywords: Public health; Epidemiology; Vaccination coverage.

\section{Resumen}

Objetivo: analizar las coberturas de vacunación en el municipio de Río de Janeiro, relacionadas por grupos de edad, en el período 2013-2019. Metodología: estudio descriptivo, ecológico, analítico, cuantitativo y transversal. Cálculo de la cobertura vacunal a través de la relación entre las dosis aplicadas, disponible en la web de libre acceso del Ministerio de Salud, Departamento de Informática del Sistema Único de Salud (DATASUS / TABNET) y población 
diana, registrada en el Sistema de Información de Nacidos Vivos (SINASC) o estimaciones de población encontradas en la Fundación Instituto Brasileño de Geografía y Estadística (IBGE). Resultados: los indicadores obtenidos para inmunobiológicos que componen el calendario de vacunación de recién nacidos, niños y adolescentes revelan un escenario preocupante de acentuación de la caída de las coberturas de vacunación, según cada grupo de edad, con pocos indicadores de éxito. Conclusión: los resultados de este estudio destacan la caída en la cobertura de vacunación para algunas vacunas y grupos de edad. Indica la necesidad de estudios para investigar las razones que han llevado a esta caída en la cobertura de vacunación.

Palabras clave: Salud pública; Epidemiología; Cobertura de vacunación.

\section{Introdução}

Notoriamente, o Brasil é um país de dimensões continentais e de um processo de construção populacional heterogêneo, dotado também de uma ampla diversidade cultural e socioeconômica e, mediante a esse panorama, o impacto de algumas informações ou de notícias tendenciosas podem gerar consequências desastrosas.

No cenário da vacinação no Brasil, é interessante destacar, por exemplo, que, desde a década de 1990, as coberturas vacinais infantis se mantinham acima de $95 \%$ (Domingues \& Teixeira, 2013), indicando uma boa adesão da população às propostas e movimentos relacionados a vacina. No entanto, a partir de 2016, observou-se uma queda, considerada inesperada, de 10 a 20 pontos percentuais nessas coberturas. Os casos de sarampo se destacando no cenário nacional são consequências imediatas dessa diminuição de coberturas vacinais (Sato, 2018).

Nesse contexto, o Ministério da Saúde (MS), como tentativa de traduzir a realidade e chamar atenção para o problema, publicou um Manifesto em parceria das Sociedades Brasileiras de Pediatria (SBP), Imunizações (SBIm), Infectologia (SBI) e com a Rotary Internacional com o apoio do Plano Nacional de Imunização (PNI), com um alerta a respeito do risco do retorno da poliomielite e da reemergência do sarampo (Constantino et al, 2018). Além disso, devido a essa mesma preocupação, foi lançado um relatório o qual faz referência ao questionamento sobre os motivos de existir a chamada “hesitação vacinal”, deduzindo que essas razões são complexas e variadas (OMS, 2019).

Diversos fatores estão em discussão por estarem relacionados a queda da cobertura vacinal no país. Vão desde o desmonte do Sistema Único de Saúde (SUS), passando pelas questões técnicas (como a implantação do novo sistema de informação de imunização), pelas características, diferenças e contrastes do nosso território, e pelos aspectos sociais e culturais, que afetam a aceitação da vacinação (Sato, 2018; Domingues \& Teixeira, 2013; Barbieri \& Couto, 2015; Barbieri \& Couto, 2017; Aps et al., 2018; Succi, 2018).

Desse modo, há necessidade de compreendermos a existência da Lei Orgânica da Saúde, composta pela Lei 8.080 (Brasil, 1990a) e pela Lei 8.142 (Brasil, 1990b), e de que modo ela pode contribuir para o alcance dos cidadãos aos direitos por elas atribuídos.

Assim, é preciso reconhecer a profundidade da saúde como um direito fundamental do ser humano, devendo o Estado prover as condições indispensáveis ao seu pleno exercício, além de garantir uma saúde constituída de políticas econômicas e sociais que visem à redução de riscos de doenças e de outros agravos, e no estabelecimento de condições que assegurem acesso universal e igualitário às ações e aos serviços para a sua promoção, proteção e recuperação. Mais ainda, a Lei Orgânica também busca esclarecer a participação da comunidade na gestão do Sistema Único de Saúde (SUS), bem como as transferências intergovernamentais de recursos financeiros na área da saúde (Brasil, 1990a; Brasil, 1990b).

Frequentemente, o primeiro contato do usuário, exercendo o seu direito de acesso à saúde, se dará ao adentrar à unidade básica de saúde (UBS). Por esse ângulo, a relação que a imunização estabelece com a atenção primária (AP) é de extrema valia, visto que para a PNAB - 2017 a AP é a porta de entrada preferencial do sistema que deve ordenar os fluxos e contrafluxos de pessoas, sendo assim, esta possui a qualificação para ordenar e assistir a população no que diz respeito a campanhas de imunização e aplicação das vacinas estabelecidas pelo calendário nacional de imunização. Dessa forma, 
devemos "reconhecer e reafirmar a vacinação como ação intrinsecamente vinculada à atenção básica em saúde como um cuidado preventivo de promoção e de proteção da saúde, oferecido, de modo geral, na porta de entrada do SUS” (Brasil, 2017).

Mediante as políticas públicas de saúde empregadas nas dimensões territoriais do Brasil, bem como a compreensão de que estas ainda possuem desafios para serem implementadas, ainda que muitas adversidades tenham sido superadas, o conhecimento das questões epidemiológicas características desse território multifacetado e heterogêneo buscam nortear o entendimento a respeito desse espaço. Em relação ao território como objeto centrado em suas atribuições etimológicas, ele mesmo é:

O chão e mais a população [...], o fato e o sentimento de pertencer àquilo que nos pertence. O território é a base do trabalho, da residência, das trocas materiais e espirituais e da vida, sobre os quais ele influi. Quando se fala em território deve-se, pois, de logo, entender que se está falando em território usado, utilizado por uma dada população (Santos \& Silveira, 2001).

Esse panorama é retratado a partir das observações encontradas no espaço delimitado pelo estudo, sendo orientada pelas definições de território e pela organização de sua população. A relação entre esses dois elementos torna-se aplicável ao município do Rio de Janeiro, composto por um desenvolvimento histórico marcado pela ocupação irrestrita e desordenada, além de uma urbanização recente e discriminatória.

O resultado dessa urbanização é observado facilmente ao analisar o espaço geográfico ocupado pelo município do Rio de Janeiro, o qual o consiste em uma diferenciação completa entre a população que reside na porção de asfalto e população que reside nas encostas, nas porções elevadas e nas periferias. Essa ocupação irrestrita aos morros gerou o processo de "favelização", dando início a formas de habitação alternativas para àqueles que perderam suas casas e não tinham poder financeiro para habitar os novos prédios que surgiriam no mesmo local antes ocupados pelos cortiços, além de que morar nos morros, também permitiria continuar próximo aos locais de trabalho (Alvito \& Zalur, 2003).

A consequência disso é refletida nos habitantes, que invariavelmente já possuem dificuldades de acesso aos serviços de saúde, visto que, como a população é majoritariamente de classe baixa, a restrição de aporte financeiro para essa área tende a marginalizar cada vez mais essa população mais pobre. E não é apenas a saúde que fica em segundo plano, mas também a educação, sendo assim, a restrição ao aprendizado somado a ampla disseminação do acesso à informação digital, nem sempre geram uma relação positiva, porquanto, é necessário, muitas vezes, uma análise crítica dos conteúdos divulgados pela internet.

Baseado nisso, nota-se a relevância em produzir conhecimento sobre os indicadores de saúde referentes à imunização. Há também preocupação em buscar as causas relacionadas à queda da cobertura vacinal, no município do Rio de Janeiro, tendo por objetivo analisar a cobertura vacinal no munícipio do Rio de Janeiro, relacionadas às faixas etárias, no período de 2013 2019.

A proposta do estudo possibilita reflexões sobre as possíveis razões que corroboram para as alterações nos indicadores de cobertura vacinal, além de nortear outras pesquisas no mesmo segmento e produzir dados significativos que tendem a possibilitar mudanças no cenário da queda dos indicadores e, por consequência, aumentar a imunização no território brasileiro.

Apesar da importância aos procedimentos e protocolos, e toda a lógica burocrática organizacional que a implementação do calendário vacinal e acompanhamento dos indicadores vacinais requerem, coletar informações para aprofundamento nas formas de entender e aplicar as recomendações dos órgãos de saúde possibilita também a multiplicidade de dimensões de saberes e fazeres que perfazem os sujeitos sociais (Merhy et al., 2016). 


\section{Metodologia}

Estudo descritivo ecológico, analítico, do tipo quantitativo e transversal, abrangendo o município do Rio de Janeiro, no período compreendido entre os anos de 2013 a 2019. Não foram selecionados os anos de 2020 e 2021, pois até o momento da coleta, estes dados não estavam disponíveis de forma completa nos sítios de busca utilizados pela pesquisa, o que tornaria a análise inconsistente pela falta de informações (Richardson, 1999).

Nos estudos ecológicos, a ideia é fazer uma discussão entre a ocorrência da doença/condição relacionada à saúde e a exposição de interesse entre agregados de indivíduos (população de município, como delimitado para este estudo) para verificar a possível existência de associação entre elas. Uma das suas vantagens é a possibilidade de examinar associações entre exposição e doença/condição relacionada a coletividade. Isso é particularmente importante quando se considera que a expressão coletiva de um fenômeno pode diferir da soma das partes do mesmo fenômeno (Lima-Costa \& Barreto, 2003).

As coberturas vacinais foram calculadas por meio da razão entre o número de doses aplicadas e a população alvo. Os valores utilizados para contabilizar as coberturas foram calculados a partir do total de últimas contidas no esquema vacinal de cada vacina. A respeito da população alvo, esta foi obtida por meio do agrupamento por faixa etária, composto pelo número de nascimentos registrados no Sistema de Informações sobre Nascidos Vivos (SINASC), para os recém-nascidos até um ano de idade. Para as demais idades, a população alvo foi adquirida por meio de estimativas populacionais, fornecidas pela Fundação Instituto Brasileiro de Geografia e Estatística (IBGE). Ambos disponíveis no sítio eletrônicos de acesso livre do Ministério da Saúde, Departamento de Informática do Sistema Único de Saúde (DATASUS/TABNET), para análise de incidência e Cobertura Vacinal. As estimativas populacionais são referentes a População Residente no munícipio do Rio de Janeiro, seguindo os critérios definidos pelo próprio IBGE.

Nesses moldes, os dados foram construídos e organizados por meio de perfis de taxas vacinais, definidos por grupos referentes a cada faixa etária, que receberam o esquema completo de vacinação, sendo o esquema completo todas as vacinas preconizadas pelo PNI, cujas doses foram aplicadas nas idades adequadas e dentro do intervalo preconizado.

Em vista disso, os indicadores foram organizados em 3 grupos, conforme disponibilizado pelo Calendário Vacinal Online do Ministério da Saúde: recém-nascidos (ao nascer até um ano de idade), crianças ( 2 a 4 anos de idade) e adolescente ( 9 a 19 anos) (Brasil, 2020). Esses agrupamentos definidos por faixa etária foram correlacionados às aplicações das vacinas correspondentes as idades de referência preconizadas pelo PNI, bem como seguindo os intervalos adequados para cada dose. Com exceção dos imunobiológicos BCG e Hepatite B, as demais vacinas, referentes aos grupos de crianças com idade em meses, não foram contempladas devido à dificuldade de encontrar a população alvo dessa faixa etária específica, ou seja, não foi encontrado o valor aproximado desse grupo de população.

Faz-se uma ressalva em relação ao esquema vacinal preconizado pelo PNI, pois nem todas as vacinas contempladas pelo plano estão notificadas pelo sistema de informação e disponíveis para consulta, sendo tais disponibilidades ausentes ou parciais, ao exemplo do imunobiológico para HPV, que não havia notificações suficientes para ser representado.

Os dados coletados foram transferidos e tabulado em formato de planilha do programa Excel - versão definitiva 2019. Realizou-se as análises descritivas e foi obtido resultados compostos por frequências absolutas, relativas e medidas de tendências centrais, utilizando o Software Programa R @ versão 3.5.1.

\section{Resultados e Discussão}

Considerou-se a cobertura vacinal como a proporção em percentil da população específica que recebeu o esquema completo de vacinação previsto pelo Programa Nacional de Imunização (PNI) em relação ao total da sua respectiva população e faixa etária, que deveria ter sido imunizada, dentro de um tempo e um espaço geográfico delimitado (Brasil, 2015). 
Observa-se que a cobertura vacinal do grupo de recém-nascidos correspondente ao imunobiológico BCG possui valores de doses aplicadas denominada por Frequência Absoluta (N) superiores aos nascidos-vivos para os anos de 2015-2018 como representado na Tabela 1. Dessa forma, explica-se o fato da Frequência Relativa (\%) exceder o percentil. Buscou-se compreender os motivos para que isso tenha ocorrido por meio da avaliação de estudos sobre a mesma temática, que avaliam a cobertura em âmbito nacional. Uma possibilidade, por exemplo, seria a aplicação de doses em recém natos que vêm com suas famílias de munícipios vizinhos para serem vacinados em Unidades Básicas de Saúde do munícipio do Rio de Janeiro, porém, não há uma resposta concreta a esse fato (Arroyo et al., 2020; Moraes et al., 2003).

Ainda acerca da Tabela 1, apesar dessa inconsistência, percebe-se também que os anos em que elas não ocorreram 2013, 2014 e 2019, os valores obtidos demostraram que a cobertura desse imunobiológico é alta, com uma média de 93.982,28 de doses aplicadas durante o período citado e mediana de 91.685,5. Esse resultado corrobora com as evidências demonstradas no estudo encontrado por revisão de literatura. Tal estudo aponta que a BCG, entre os anos de 2006 a 2016, obteve média de $81,1 \%$. Isso comprava o fato de a cobertura vacinal ser considerada de ampla escala para esse grupo (Arroyo et al., 2020).

Por sua vez, o imunobiológico para Hepatite B apresenta valores inferiores ao anterior, destacando-se o ano de 2016, em que o percentual foi de $0,8 \%$ com apenas 720 crianças vacinadas para o imunobiológico citado. Ressalta-se ainda a média de $6.793,28$ e mediana de 573 , sendo estas consideradas baixas.

Tabela 1 - Frequência Absoluta, Frequência Relativa e Medidas Centrais para o grupo de Recém-nascidos.

Imunobiológicos

Frequência Absoluta (N) /

Frequência Relativa (\%)
Desvio

Média Mediana Padrão

(sd)

\begin{tabular}{|c|c|c|c|c|c|c|c|c|c|c|}
\hline & 2013 & 2014 & 2015 & 2016 & 2017 & 2018 & 2019 & & & \\
\hline \multirow{2}{*}{ BCG } & $90.383 /$ & 92.988/ & $102.079 /$ & $99.192 /$ & $114.134 /$ & $94.575 /$ & $64.525 /$ & \multirow{2}{*}{$93.982,28$} & \multirow{2}{*}{$91.685,5$} & \multirow{2}{*}{$15.170,23$} \\
\hline & 97 & 98 & 106 & 110 & 123 & 105 & 74 & & & \\
\hline \multirow{2}{*}{ Hepatite B } & $40.817 /$ & $1.927 /$ & 2.481/ & $720 /$ & $1.040 /$ & $426 /$ & $142 /$ & \multirow{2}{*}{$6.793,28$} & \multirow{2}{*}{573} & \multirow{2}{*}{$15.025,85$} \\
\hline & 46 & 2 & 2 & 0.8 & 1 & 0.4 & 0.1 & & & \\
\hline
\end{tabular}

Fonte: DATASUS/TABNET. Tabela elaborada pelos autores.

Para as vacinas Pentavalente e Pneumocócica 10 Valente Conjugada, a mesma inconsistência ocorrida com a BCG foi detectada para os valores obtidos por intermédio da base de dados governamental, visto que o total de doses aplicadas foram superiores as crianças correspondentes para sua faixa etária, neste caso, 2 meses de idade para ambas.

Desse modo, os valores apresentados pela Tabela 2 também ultrapassam o percentil determinado. No imunobiológico denominado VIP/VOP, utilizado para prevenir a poliomielite, o problema ocorre de forma parcial no ano de 2016 em diante. Entretanto, ainda assim, destaca-se também uma cobertura ampla para o grupo analisado. Assim, também corrobora com outros resultados semelhantes, tendo como perspectiva o Brasil, cujo valor obtido para a cobertura vacinal, no mesmo período indicado anteriormente (2006-2016) de 91\% (Arroyo et al., 2020).

O imunológico responsável pela prevenção de infeção viral por Hepatite A possui, em 2013, apontava valores considerados baixos (4\%). Todavia, ao longo do período analisado, nota-se um crescimento dos valores associado a momentos de oscilação. O mesmo comportamento se encontra nos resultados contextualizados ao perfil nacional, que de 2014 a 2018 variou de 60,13\% (2014) a 97,07 (2015), entretanto, também apontou expressiva variação, ao exemplo de 71,58\% obtido em 2016 (Brito \& Souto, 2020). 
Para Meningocócica C e a Hepatite A nos anos de 2015 e 2017 também há uma alteração nas doses aplicadas nesse mesmo ano. O restante dos imunobiológicos representados possuem valores adequados cujas doses divulgadas não sobrepõem ao número do grupo destacado.

A vacina VORH apresentou baixos indicadores para os anos de 2014, 2018 e 2019. Todavia, é preciso enfatizar o imunobiológico que atingiu uma cobertura vacinal satisfatoriamente alta, a Tetra viral com média de 26.629 e mediana de $9.905,5$.

Outro aspecto importante analisado na Tabela 2, trata-se da dos valores de medidas centrais, identificando médias consideradas inferiores às esperadas pelo PNI. Estas compostas pela vacina contra Febre Amarela, Tríplice Viral, Dupla infantil (DTP) e Varicela com valores de 183, 775, 383 e 85,5, respectivamente. Nesse caso, é possível perceber que, em sua maioria, a adesão desses imunobiológicos era baixa no ano de 2013, porém, esse cenário passou a mudar no decorrer do tempo. Mesmo assim, esse aumento não pode ser considerado satisfatório, pois a cobertura ainda se encontra em níveis abaixo do adequado.

Tabela 2 - Frequência Absoluta, Frequência Relativa e Medidas Centrais para o grupo de crianças.

\begin{tabular}{|c|c|c|c|c|c|c|c|c|c|c|}
\hline \multirow[t]{2}{*}{ Imunobiológico } & \multicolumn{7}{|c|}{$\begin{array}{l}\text { Frequência Absoluta (N) / } \\
\text { Frequência Relativa (\%) }\end{array}$} & \multirow[t]{2}{*}{ Média } & \multirow[t]{2}{*}{ Mediana } & \multirow[t]{2}{*}{$\begin{array}{c}\text { Desvio } \\
\text { Padrão } \\
\text { (sd) }\end{array}$} \\
\hline & 2013 & 2014 & 2015 & 2016 & 2017 & 2018 & 2019 & & & \\
\hline Pentavalente & $\begin{array}{c}247.975 / \\
282\end{array}$ & $\begin{array}{c}246.970 / \\
274\end{array}$ & $\begin{array}{c}262.227 / \\
289\end{array}$ & $\begin{array}{c}268.316 / \\
322\end{array}$ & $\begin{array}{c}279.284 / \\
330\end{array}$ & $\begin{array}{c}224.650 / \\
272\end{array}$ & $\begin{array}{c}145.280 / \\
168\end{array}$ & $239.243,1$ & 235.810 & $45.008,77$ \\
\hline VIP/VOP & $\begin{array}{c}5.010 / \\
5\end{array}$ & $\begin{array}{c}2.429 / \\
2\end{array}$ & $\begin{array}{c}25.540 / \\
26\end{array}$ & $\begin{array}{c}260.935 / \\
291\end{array}$ & $\begin{array}{c}271.299 / \\
293\end{array}$ & $\begin{array}{c}222.542 / \\
248\end{array}$ & $\begin{array}{c}170.922 / \\
198\end{array}$ & $136.953,85$ & 15.275 & $122.350,8$ \\
\hline $\begin{array}{c}\text { Pneumocócica } \\
10 \text { valente } C .\end{array}$ & $\begin{array}{c}245.169 / \\
265\end{array}$ & $\begin{array}{c}246.262 / \\
261\end{array}$ & $\begin{array}{c}257.303 / \\
267\end{array}$ & $\begin{array}{c}191.988 / \\
214\end{array}$ & $\begin{array}{c}187.537 / \\
202\end{array}$ & $\begin{array}{c}156.871 / \\
175\end{array}$ & $\begin{array}{c}121.949 / \\
141\end{array}$ & $201.011,3$ & 172.204 & $51.036,7$ \\
\hline $\begin{array}{c}\text { Meningocócica } \\
\text { C. }\end{array}$ & $\begin{array}{c}75.391 / \\
81\end{array}$ & $\begin{array}{c}75.355 / \\
80\end{array}$ & $\begin{array}{c}80.694 / \\
85\end{array}$ & $\begin{array}{c}99.865 / \\
111\end{array}$ & $\begin{array}{c}82.527 / \\
89\end{array}$ & $\begin{array}{c}61.94 / \\
69\end{array}$ & $\begin{array}{c}56.516 / \\
65\end{array}$ & $76.041,14$ & 172.204 & $51.036,7$ \\
\hline Febre Amarela & $\begin{array}{c}179 / \\
0.0019\end{array}$ & $\begin{array}{c}187 / \\
0.0019\end{array}$ & $\begin{array}{c}163 / \\
0.0016\end{array}$ & $\begin{array}{c}210 / \\
0.0023\end{array}$ & $\begin{array}{c}24.276 / \\
0.26\end{array}$ & $\begin{array}{c}40.602 / \\
0.45\end{array}$ & $\begin{array}{c}57.024 / \\
0.66\end{array}$ & $17.520,14$ & 183 & $23.597,43$ \\
\hline Tríplice Viral & $\begin{array}{c}535 / \\
0.5\end{array}$ & $\begin{array}{c}826 / \\
0.8\end{array}$ & $\begin{array}{c}1.192 / \\
1.2\end{array}$ & $\begin{array}{c}724 / \\
0.8\end{array}$ & $\begin{array}{c}888 / \\
0.9\end{array}$ & $\begin{array}{c}1.420 / \\
1.5\end{array}$ & $\begin{array}{c}44.065 / \\
51\end{array}$ & $7.092,85$ & 775 & $16.305,83$ \\
\hline Dupla Infantil & $\begin{array}{c}522 / \\
0.5\end{array}$ & $\begin{array}{c}850 / \\
0.9\end{array}$ & $\begin{array}{c}584 / \\
0.6\end{array}$ & $\begin{array}{c}24 / \\
0.004\end{array}$ & $\begin{array}{c}244 / \\
0.2\end{array}$ & $\begin{array}{l}74 / \\
0.8\end{array}$ & $\begin{array}{c}528 / \\
0.6\end{array}$ & 499,28 & 383 & 283,42 \\
\hline Hepatite A & $\begin{array}{c}4.018 / \\
4\end{array}$ & $\begin{array}{c}62.029 / \\
65\end{array}$ & $\begin{array}{c}100.840 / \\
104\end{array}$ & $\begin{array}{c}79.083 / \\
88\end{array}$ & $\begin{array}{c}99.774 / \\
107\end{array}$ & $\begin{array}{c}84.441 / \\
91\end{array}$ & $\begin{array}{c}73.858 / \\
85\end{array}$ & $72.006,14$ & $67.943,5$ & $32.996,24$ \\
\hline Tetra viral & $\begin{array}{c}16.641 / \\
18\end{array}$ & $\begin{array}{c}71.269 / \\
75\end{array}$ & $\begin{array}{c}61.525 / \\
64\end{array}$ & $\begin{array}{c}555 / \\
0.6\end{array}$ & $\begin{array}{c}16.602 / \\
17\end{array}$ & $\begin{array}{c}7.574 / \\
8\end{array}$ & $\begin{array}{c}12.237 / \\
14\end{array}$ & 26.629 & $9.905,5$ & $27.871,24$ \\
\hline Varicela & $\begin{array}{l}39 / \\
0.04\end{array}$ & $\begin{array}{c}8 / \\
0.008\end{array}$ & $\begin{array}{c}130 / \\
0.1\end{array}$ & $\begin{array}{c}290 / \\
0.3\end{array}$ & $\begin{array}{c}327 / \\
0.3\end{array}$ & $\begin{array}{c}477 / \\
0.5\end{array}$ & $\begin{array}{c}167 / \\
0.1\end{array}$ & 205,42 & 84,5 & 168,09 \\
\hline
\end{tabular}


Para o grupo de adolescentes, cujas vacinas contemplam sua faixa etária específica, da mesma maneira que nos grupos anteriores, não foi possível encontrar os dados das doses aplicadas do imunobiológico Dupla Adulto (dT/dTpa). No entanto, as demais vacinas preconizadas foram obtidas e dispostas na Tabela 3. Nessa tabela também é possível notar a superestimação do Imunobiológico Meningocócica C., descrevendo valores acima do percentil como relatado anteriormente.

Por outro lado, as vacinas Hepatite B, Febre Amarela e Pneumocócica 23 valente demostraram possuir uma cobertura vacinal mais ampla com médias de 403.872,71; 511.400,71 e 10.462,85. Além de disso, a mediana de ambas também apresenta esse mesmo raciocínio com os valores de 303.125; 52.549,5 e 8.353,5, respectivamente.

A exceção se nota na vacina Tríplice Viral, imunobiológico responsável pela prevenção de 3 doenças: sarampo, caxumba e rubéola (Brasil, 2020). Sua média e mediana, como mostrado na Tabela 3, são baixas, com valores de 1.373,28 e 564,5 , nessa ordem.

Nesse sentido, é possível inferir que o grupo pertencente aos adolescentes é aquele que possui de modo mais aproximado os melhores indicadores para cobertura vacinal mais ampla e mais abrangente, ainda que os em termos absolutos e relativos esses valores sejam considerados insuficientes se comparados ao número total da população referente a sua determinada faixa etária e espaço de tempo considerados. Outro fator relevante diz respeito aos desvios-padrões que, em grande parte, mostram-se de sobremaneira elevados, evidenciado uma dispersão ampla dos valores de dose aplicadas durante o período determinado - um período considerado longo 2013 - 2019. Esse fato indica que para uma mesma vacina, a adesão se modificou ao longo dos anos, variando com momentos de queda e de aumento no período delimitado pela pesquisa.

Isso pode significar as mudanças vivenciadas pelos sistemas de informação oficiais do governo que em certos anos apresentam uma notificação mais engajada, enquanto em outros anos menos, visto que quanto maior o espaço amostral, maior é a visualização das mudanças ora decorrentes desse processo.

Por consequência disso, é notório o impacto das subnotificações no desenvolvimento de estratégias, não só para a Secretária de Vigilância em Saúde (SVS), mas também para as pesquisas dentro da temática de cobertura vacinal.

Tabela 3 - Frequência Absoluta, Frequência Relativa e Medidas Centrais para o grupo de adolescente.

\begin{tabular}{|c|c|c|c|c|c|c|c|c|c|c|}
\hline \multirow[t]{2}{*}{ Imunobiológicos } & \multicolumn{7}{|c|}{$\begin{array}{l}\text { Frequência Absoluta (N) / } \\
\text { Frequência Relativa (\%) }\end{array}$} & \multirow[t]{2}{*}{ Média } & \multirow[t]{2}{*}{ Mediana } & \multirow[t]{2}{*}{$\begin{array}{c}\text { Desvio } \\
\text { Padrão } \\
\text { (sd) }\end{array}$} \\
\hline & 2013 & 2014 & 2015 & 2016 & 2017 & 2018 & 2019 & & & \\
\hline $\begin{array}{l}\text { Meningocócica } \\
\text { C. }\end{array}$ & $\begin{array}{c}173.264 / \\
2.6\end{array}$ & $\begin{array}{c}171.310 / \\
2.6\end{array}$ & $\begin{array}{c}183.977 / \\
2.7\end{array}$ & $\begin{array}{c}180.279 / \\
2.7\end{array}$ & $\begin{array}{c}178.212 / \\
2.6\end{array}$ & $\begin{array}{c}151.603 / \\
2.2\end{array}$ & $\begin{array}{c}118.604 / \\
1.7\end{array}$ & $165.321,28$ & $161.456,5$ & $23.121,37$ \\
\hline Hepatite B & $\begin{array}{c}514.983 / \\
7\end{array}$ & $\begin{array}{c}567.507 / \\
8\end{array}$ & $\begin{array}{c}489.661 / \\
7\end{array}$ & $\begin{array}{c}331.414 / \\
4\end{array}$ & $\begin{array}{c}394.691 / \\
5\end{array}$ & $\begin{array}{c}274.836 / \\
4\end{array}$ & $\begin{array}{c}254.017 / \\
3\end{array}$ & $403.872,71$ & 303.125 & $123.100,96$ \\
\hline Febre Amarela & $\begin{array}{c}58.665 / \\
0.8\end{array}$ & $\begin{array}{c}60.766 / \\
0.9\end{array}$ & $\begin{array}{c}46.434 / \\
0.7\end{array}$ & $\begin{array}{c}45.975 / \\
0.6\end{array}$ & $\begin{array}{c}2.125 .467 / \\
31\end{array}$ & $\begin{array}{c}1.075 .950 / \\
16\end{array}$ & $\begin{array}{c}166.548 / \\
2.4\end{array}$ & $511.400,71$ & $52.549,5$ & $804.539,79$ \\
\hline Tríplice Viral & $\begin{array}{l}529 / \\
0.008\end{array}$ & $\begin{array}{c}600 / \\
0.009\end{array}$ & $\begin{array}{c}1.362 / \\
0.18\end{array}$ & $\begin{array}{c}4.268 / \\
0.01\end{array}$ & $\begin{array}{c}1.664 / \\
0.13\end{array}$ & $\begin{array}{l}741 / \\
0.02\end{array}$ & $\begin{array}{c}449 / \\
0.6\end{array}$ & $1.373,28$ & 564,5 & $1.355,78$ \\
\hline $\begin{array}{l}\text { Pneumocócica } \\
23 \text { valente }\end{array}$ & $\begin{array}{c}6.771 / \\
0.1\end{array}$ & $\begin{array}{c}8.456 / \\
0.12\end{array}$ & $\begin{array}{c}11.416 / \\
0.17\end{array}$ & $\begin{array}{c}13.675 / \\
0.2\end{array}$ & $\begin{array}{c}14.306 / \\
0.21\end{array}$ & $\begin{array}{c}10.365 / \\
0.15\end{array}$ & $\begin{array}{c}8.251 / \\
0.12\end{array}$ & $10.462,85$ & $8.353,5$ & $2.844,74$ \\
\hline
\end{tabular}




\section{Considerações Finais}

Os resultados desse estudo destacam, por meio dos indicadores de cobertura vacinal, segundo faixas etárias, o cenário de alerta em que se encontra o munícipio do Rio de Janeiro. Dessa forma, justifica-se a preocupação das entidades de saúde e profissionais de referência em vigilância epidemiológica e imunização com relação a diminuição da cobertura vacinal em alguns grupos de população, principalmente os retratados pelas crianças.

É possível afirmar que a cada ano que passou, desde 2013, os valores possuem um retrato que chama a atenção pela queda sensível para alguns imunobiológicos como, por exemplo, aquele que previne febra amarela, uma doença de alta incidência e prevalência no Brasil, considerada erradicada em outros continentes.

As evidências encontradas no que diz respeito à baixa cobertura vacinal no município do Rio de Janeiro devem servir de base para o fortalecimento do monitoramento dessas informações, para subsidiar discussões sobre a cobertura da Estratégia de Saúde da Família, assim como para o fortalecimento do vínculo com a população.

Outro fato importante observado durante o estudo são os casos recorrentes de subnotificações encontradas nas bases vinculadas aos endereços eletrônicos governamentais, sendo assim, o reflexo dessas informações parciais influencia diretamente não apenas nas pesquisas de temática similar, mas também no desenvolvimento organizacional das entidades de vigilância do país.

Portanto, torna-se de extrema valia a complementação desses achados por outras pesquisas sobre o tema, tendo por intuito descobrir os reais motivos que contribuem para a hesitação vacinal ou ainda as razões que favorecem a não vinculação desse usuário(a) e dos seus filhos ao calendário vacinal, sendo este indispensável como medida segura de prevenção contra doenças e de promoção a saúde.

\section{Referências}

Alvito, M., \& Zalur, A. (orgs) (2003). Um Século de Favela. (3a ed.), Editora FGV.

Aps, L. R. M. M., Piantola, M. A. F., Pereira, S., Castro, J. T., Santos, F. A. O., \& Ferreira, L. C. S. (2018). Adverse events of vaccines and the consequences of non-vaccination: a critical review. Rev Saude Publica. 52:40.

Arroyo, L. H., Ramos, A. C. V., Yamamura, M., Weiller, T. H., Crispim, J. Á., Cartagena-Ramos, D. et al. (2020). Áreas com queda da cobertura vacinal para BCG, poliomielite e tríplice viral no Brasil (2006-2016): mapas da heterogeneidade regional. Cad. Saúde Pública. 36(4): e00015619.

Barbieri, C. L. A., \& Couto, M. T. (2015). Decision-making on childhood vaccination by highly educated parents. Rev Saude Publica. 49 :18.

Barbieri, C. L. A., Couto, M. T., \& Aith, F. M. A. (2017). A (não) vacinação infantil entre a cultura e a lei: os significados atribuídos por casais de camadas médias de São Paulo, Brasil. Cad Saude Publica. 33(2):e00173315.

Brasil (1990a). Lei 8.080, de 19 de setembro de 1990. Dispõe sobre as condições para a promoção, proteção e recuperação da saúde, a organização e o funcionamento dos serviços correspondentes e dá outras providências. Diário Oficial da União. http://www.planalto.gov.br/ccivil_03/leis/18080.htm.

Brasil (1990b). Lei 8.142, de 28 de dezembro de 1990. Dispõe sobre a participação da comunidade na gestão do Sistema Único de Saúde e sobre as transferências intergovernamentais de recursos financeiros na área da saúde e dá outras providências. Diário Oficial da União. http://www.planalto.gov.br/ccivil_03/leis/L8142.htm.

Brasil. Ministério da Saúde. (2015). Coberturas vacinais no Brasil. Período: 2010-2014. https://portalarquivos2.saude.gov.br/images/pdf/2017/ agosto/17/AACOBERTURAS-VACINAIS-NO-BRASIL---2010-2014.pdf

Brasil. Ministério da Saúde (2017). Portaria n 2.436, de 21 de setembro de 2017. Aprova a Política Nacional de Atenção Básica, estabelecendo a revisão de diretrizes para a organização da Atenção Básica, no âmbito do Sistema Único de Saúde. Ministério da Saúde. Diário Oficial da União.

Brasil. Ministério da Saúde. (2020) Calendário Nacional de Vacinação. Ministério da Saúde.

Brito, W. I., \& Souto, F. J. D. (2020). Vacinação universal contra hepatite A no Brasil: análise da cobertura vacinal e da incidência cinco anos após a implantação do programa. Rev. bras. epidemiol. 23: e200073.

Constantino, C., Ballalai, I., Cimerman, S., Haick, M., \& Domingues, C. M. (2018). Manifesto SBIm, SBI, SBP e Rotary International. https://www.sbp.com.br/fileadmin/user_upload/Manifesto_Sociedades_Rotary_e_PNI_-_Final_-_formatado-v2.pdf.

Domingues, C. M. A. S., \& Teixeira, A. M. S. (2013). Coberturas vacinais e doenças imunopreveníveis no Brasil no período 1982-2012: avanços e desafios do Programa Nacional de Imunizações. Epidemiol Serv Saude. 22(1):9-27. 
Research, Society and Development, v. 10, n. 11, e110101119416, 2021

(CC BY 4.0) | ISSN 2525-3409 | DOI: http://dx.doi.org/10.33448/rsd-v10i11.19416

Lima-Costa, M. F., \& Barreto, S. M. (2003). Tipos de estudos epidemiológicos: conceitos básicos e aplicações na área do envelhecimento. Epidemiologia e Serviços de Saúde, 12(4): 189 - 201.

Merhy, E. E. et al (2016). Redes vivas: multiplicidades girando as existências, sinais da rua. Implicações para a produção do conhecimento em saúde. In: Merhy, E. E. et al. Avaliaçao compartilhada do cuidado em saúde: surpreendendo o instituído nas redes. Hexis.

Moraes, J. C., Almeida, R. M. C. S., Simões, O., Castro, P. C., \& Barata, R. B. (2003) Qual é a cobertura vacinal real? Epidemiol. Serv. Saúde. 12(3): 147-153.

Organização Mundial da Saúde (2019). Os 10 Desafios para a Saúde em 2019. Estados Unidos: WHO. https://www.who.int/emergencies/ten-threats-toglobal-health-in-2019.

Richardson, R. J. (1999). Pesquisa social: métodos e técnicas. Atlas.

Santos, M., \& Silveira, M. L. (2001). O Brasil: território e sociedade no início do século XXI. (19a ed.), Record.

Sato, A. P. S. (2018). Qual a importância da hesitação vacinal na queda das coberturas vacinais no Brasil?. Revista de Saúde Pública, $52,96$.

Succi, R. C. M. (2018). Vaccine refusal: what we need to know. J Pediatr (Rio J). 94(6). 